Health Services Research

\title{
Patterns of Long-Term Prescription Opioid Use Among Older Adults in the United States: A Study of Medicare Administrative Claims Data
}

\author{
Sujith Ramachandran, PhD'1, Monika Salkar, MS', John P. Bentley, PhD1, Ike Eriator, MD², \\ and Yi Yang, MD, PhD ${ }^{1}$
}

From: 'Department of Pharmacy Administration, University of

Mississippi School of Pharmacy,

University, MS; ${ }^{2}$ Department of Anesthesiology, School of Medicine, University of Mississippi Medical Center, Jackson, MS

Address Correspondence: Yi Yang, MD, PhD

Department of Pharmacy Administration

University of Mississippi School of Pharmacy, Faser 232 University, MS 38677

E-mail: yiyang@olemiss.edu

Disclaimer: This study was funded by the National Institutes of Drug Abuse (R15DA046036).

The funding organization

had no role in the design and conduct of the study; collection,

management, analysis, and

interpretation of the data; preparation, review, or approval of the manuscript; and decision

to submit the manuscript for publication.

Conflict of interest: SR reports receipt of a research grant from Radius Inc.

Manuscript received: 04-22-2020 Revised manuscript received: o6-11-2020

Accepted for publication: 07-13-2020

Free full manuscript: www.painphysicianjournal.com
Background: Long-term opioid therapy was prescribed with increasing frequency over the past decade. However, factors surrounding long-term use of opioids in older adults remains poorly understood, probably because older people are not at the center stage of the national opioid crisis.

Objectives: To estimate the annual utilization and trends in long-term opioid use among older adults in the United States.

Study Design: Retrospective cohort study.

Setting: Data from Medicare-enrolled older adults.

Methods: This study utilized a nationally representative sample of Medicare administrative claims data from the years 2012 to 2016 containing records of health care services for more than 2.3 million Medicare beneficiaries each year. Medicare beneficiaries who were 65 years of age or older and who were enrolled in Medicare Parts A, B, and D, but not Part C, for at least 10 months in a year were included in the study. We measured annual utilization and trends in new long-term opioid use episodes over 4 years (2013-2016). We examined claims records for the demographic characteristics of the eligible individuals and for the presence of chronic non-cancer pain (CNCP), cancer, and other comorbidities.

Results: From 2013 to 2016, administrative claims of approximately 2.3 million elderly Medicare beneficiaries were analyzed in each year with a majority of them being women ( 56\%) and white $(\sim 82 \%)$ with a mean age of approximately 75 years. The proportion of all eligible beneficiaries with at least one new opioid prescription increased from $6.64 \%$ in 2013 , peaked at $10.32 \%$ in 2015 , and then decreased to $8.14 \%$ in 2016 . The proportion of individuals with long-term opioid use among those with a new opioid prescription was $12.40 \%$ in 2013 and $10.20 \%$ in 2016 . Among new long-term opioid users, the proportion of beneficiaries with a cancer diagnosis during the study years increased from $13.30 \%$ in 2013 to $15.67 \%$ in 2016, and the proportion with CNCP decreased from $30.25 \%$ in 2013 to $27.36 \%$ in 2016 . Across all years, long-term opioid use was consistently high in the Southern states followed by the Midwest region.

Limitations: This study used Medicare fee-for-service administrative claims data to capture prescription fill patterns, which do not allow for the capture of individuals enrolled in Medicare Advantage plans, cash prescriptions, or for the evaluation of appropriateness of prescribing, or the actual use of medication. This study only examined long-term use episodes among patients who were defined as opioid-naive. Finally, estimates captured for 2016 could only utilize data from 9 months of the year to capture 90-day long-term-use episodes.

Conclusions: Using a national sample of elderly Medicare beneficiaries, we observed that from 2013 to 2016 the use of new prescription opioids increased from 2013 to 2014 and peaked in 2015. The use of new long-term prescription opioids peaked in 2014 and started to decrease from 2015 and 2016. Future research needs to evaluate the impact of the changes in new and longterm prescription opioid use on population health outcomes.

Key words: Long-term, opioids, older adults, trends, Medicare, chronic non-cancer pain, cancer, cohort study

Pain Physician 2021: 24:31-40 
$\mathrm{T}$ he prevalence of chronic pain increases with age (1). According to the 2011 National Health and Aging Trends Study, $52.9 \%$ of older adults reported burdensome pain in the last month and pain was strongly associated with decreased physical function (2). The management of chronic pain in older adults is complicated by the aging-related decline in cognitive function, changes in pharmacodynamics, and the presence of multiple comorbid conditions, resulting in under- or overtreated pain in this population and increasing the risk for therapeutic failure and adverse drug events (3). Pain treatments, particularly pharmacologic pain management with opioids, are often associated with health risks $(4,5)$. For example, patients using opioids are more like to experience constipation, cognitive impairment, falls, and respiratory depression; especially among older patients who are more likely to use more prescription medications than younger adults, leading to more drug-drug interactions with opioids (4-8). However, commonly used alternatives to opioids such as nonsteroidal anti-inflammatory drugs are associated with increased risk of gastrointestinal, cardiovascular, and hematologic adverse effects leading to difficult choices in pain management for older adults (9). Over the past 2 decades, the use of opioids and opioid-related drug overdose events among adults of any age have become a national crisis (10), but the factors surrounding long-term use of opioids in older adults remains poorly understood, probably because older people are not at the center stage of this crisis (10). However, older adults are not resistant to the national epidemic. Historical data from 1997 to 2005 have shown that long-term opioid use increased for all ages and gender with chronic non-cancer pain (CNCP), and older women had the highest rate of long-term opioid use with a prevalence of $8 \%$ to $9 \%$ in 2005 (11). A more recent study using the National Ambulatory and National Hospital Ambulatory Medical Care Survey data showed that opioid use among older adults visiting clinics increased from $4.1 \%$ in 1999 to $9.0 \%$ in 2010 (12), but no information was presented as to how many were long-term opioid uses. Understanding the current utilization patterns and trends in the long-term use of opioids among older adults can help provide benchmark data and identify areas for improvement in chronic pain management among older adults. To fill the gap in knowledge, we examined 2012 to 2016 five percent national sample of Medicare administrative claims data containing information on health services utilization for more than 2.3 million Medicare beneficiaries and estimated the annual utilization and trends in long-term opioid use among older adults in the United States.

\section{Methods}

\section{Data Source}

The 2012 to 2016 five percent national sample of Medicare administrative claims data were used for this study. The use of research identifiable files was approved by the Centers for Medicare and Medicaid Services (CMS) under a data use agreement (DUA\# $\mathrm{RSCH}-2018-52319)$ and by the institutional review board (protocol \#18-069) at the University of Mississippi. Administrative claims for services to more than 2.3 million Medicare beneficiaries in each year of data including all inpatient, outpatient, and hospice facilities were available along with prescription fill records. Beneficiary demographic and enrollment information was obtained from a Beneficiary Summary file. All claims were linked through an encrypted unique beneficiary identification number.

\section{Study Population}

The number of individuals enrolled in any Medicare plans ranged from 52.43 million in 2013 to 56.98 million in 2016. Of these, roughly two-thirds of individuals were enrolled in original Medicare, and the number of individuals enrolled in a standalone prescription drug plan (Part D) ranged from 22.66 million in 2013 to 24.83 million in 2016 (13). We used the 5\% national sample database provided by CMS, which contained at least 2.3 million enrollees for each study year. Individuals from this dataset were included in our study when they were 65 years of age or older and enrolled in Medicare Parts $A, B$, and D for at least 10 months in a year. Individuals enrolled in Medicare Advantage plans during any part of the year were excluded from the study because not all of their medical and pharmacy claims were available in the data. After applying the inclusion and exclusion criteria, the eligible population for the study ranged from 854,283 in 2013 to 920,473 in 2016.

\section{Study Measures}

The key variable of interest in this study is the presence of a new long-term opioid use episode among older adults. All prescription claims for opioid medications, both new prescriptions and refills, were identified from Medicare Part D prescription event file for each year using the appropriate National Drug Code identifiers. The generic names and summary statistics of dosages (calculated 
as morphine milligram equivalents [14]) of all opioids identified in this study can be found in the Appendix. New long-term opioid episodes were measured for each calendar year from 2013 to 2016. Informed by literature (15), a long-term opioid episode was operationalized as having 3 or more pharmacy claims for opioid medications with a cumulative 45 days of opioid supply during any 90 day period in this study (16). A long-term opioid episode was identified as "new" when the first prescription fill of the episode was preceded by 90 days with no opioid prescription fills. Figure 1 depicts the study cohort selection for measuring long-term opioid therapy. For each year, annual long-term opioid use was estimated based on all prescriptions filled by eligible individuals during the calendar year. The 90 days after each prescription, which sometimes extended into the next calendar year, was also examined to identify long-term therapy. Due to data availability, utilization estimates for 2016 were obtained using data up to September 30, 2016.

Each eligible individual's underlying pain conditions were identified during the 6 months before the index date of each episode using the International Classification of Diseases, 9th or 10th Revision, Clinical Modification (ICD-9-CM or ICD-10-CM) diagnosis codes in the medical claims obtained from all inpatient and outpatient files. To qualify as a new long-term opioid episode as being cancer-related, the individual must have at least one cancer diagnosis in the 6 months before the index date. The inclusion of CNCP conditions was informed by literature (17-23). The list of CNCP conditions is available on request. Based on the underlying diseases, each new long-term opioid therapy episode was categorized as related to

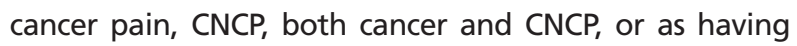
no identifiable pain conditions available in the database.

\section{Data Analyses}

All analyses were performed with SAS version 9.4 (SAS Inc, Cary, NC). All descriptive characteristics were presented for each year in the study period to accurately present trends. To adequately capture geographic variations in long-term opioid use among older adults and its trend, Geographic Information Systems was used to overlay long-term opioid use results on a map of the United States. SAS command PROC GMAP was used to achieve this purpose.

\section{RESULTS}

From 2013 to 2016, records for approximately 2.4 million elderly Medicare beneficiaries were found in each year with a majority of them being women ( $56 \%)$ and white $(\sim 82 \%)$ with a mean age of approximately 75 years (Table 1). Approximately $35.5 \%$ of all benefi-

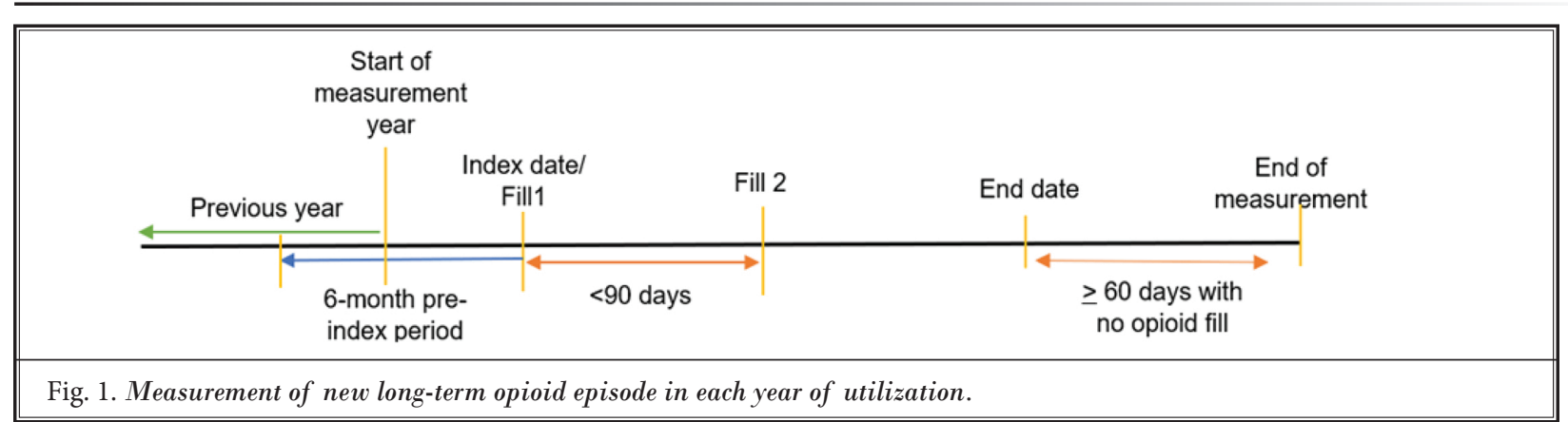

Table 1. Baseline characteristics of all Medicare beneficiaries from 5\% Medicare administrative claims by year, 2013 to 2016.

\begin{tabular}{|c|c|c|c|c|}
\hline Characteristics & 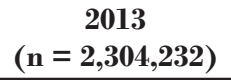 & $\begin{array}{c}2014 \\
(\mathrm{n}=\mathbf{2 , 4 0 2 , 4 1 6 )}\end{array}$ & $\begin{array}{c}2015 \\
(\mathrm{n}=\mathbf{2 , 4 8 3 , 8 7 8 )}\end{array}$ & $\begin{array}{c}2016 * \\
(n=2,572,303)\end{array}$ \\
\hline Age mean (SD) & $74.97(8.08)$ & $74.80(8.03)$ & $74.73(7.98)$ & $74.65(7.93)$ \\
\hline \multicolumn{5}{|l|}{ Gender } \\
\hline Female & $1,285,138(55.77 \%)$ & $1,342,453(55.88 \%)$ & $1,385,800(55.79 \%)$ & $1,434,283(55.76 \%)$ \\
\hline \multicolumn{5}{|l|}{ Race } \\
\hline White & $1,922,540(83.44 \%)$ & $1,991,833(82.91 \%)$ & $2,045,673(82.36 \%)$ & $2,105,947(81.87 \%)$ \\
\hline African American & $197,844(8.59 \%)$ & $208,431(8.68 \%)$ & $218,324(8.79 \%)$ & $228,268(8.87 \%)$ \\
\hline Other & $183,848(7.98 \%)$ & $202,152(8.41 \%)$ & $219,881(8.85 \%)$ & $238,088(9.26 \%)$ \\
\hline
\end{tabular}

Abbreviations: SD, standard deviation.

${ }^{\star}$ Estimates for the year 2016 were calculated using 5\% National Medicare data from January 1 through September 30, 2016. 
ciaries met the continuous enrollment criteria for each calendar year and were included in the denominator. Table 2 reports the annual opioid prescribing patterns for each year from 2013 to 2016. During this period, the proportion of all eligible beneficiaries with at least one new opioid prescription increased from $6.64 \%$ in 2013 , peaked at $10.32 \%$ in 2015 , and then decreased to $8.14 \%$ in 2016 . The proportion of all eligible Medicare beneficiaries who had a new long-term opioid use episode was $0.82 \%$ ( $n=6,738$ out of 818,701 eligible individuals) in 2013 and $0.83 \%$ ( $n=7,639$ out of 920,473 eligible individuals) in 2016 , with a high of $1.18 \%$ (n $=10,121$ out of 854,283 eligible individuals) in 2014 . Among all eligible Medicare beneficiaries with at least one new opioid prescription, 6,738 (12.40\%) had at least one new long-term opioid use in 2013, 10,121 $(12.80 \%)$ in $2014,8,829(9.65 \%)$ in 2015 , and 7,639 $(10.20 \%)$ in 2016. Because some individuals may have more than one new long-term episode in a given year, this analysis was repeated at the event level and identified 6,837 unique long-term episodes in 2013, and 7,727 new long-term opioid episodes were identified

Table 2. Annual opioid use among Medicare beneficiaries by year, 2013 to 2016.

\begin{tabular}{|l|c|c|c|c||}
\hline Population & $\mathbf{2 0 1 3}$ & $\mathbf{2 0 1 4}$ & $\mathbf{2 0 1 5}$ & $\mathbf{2 0 1 6}$ \\
\hline $\begin{array}{l}\text { Eligible } \\
\text { beneficiaries* }\end{array}$ & 818,701 & 854,283 & 887,083 & 920,473 \\
\hline $\begin{array}{l}\text { Eligible } \\
\text { beneficiaries } \\
\text { with new opioid } \\
\text { prescription } \dagger\end{array}$ & $\begin{array}{c}54,355 \\
(6.64 \%)\end{array}$ & $\begin{array}{c}79,045 \\
(9.25 \%)\end{array}$ & $\begin{array}{c}91,531 \\
(10.32 \%)\end{array}$ & $\begin{array}{c}74,881 \\
(8.14 \%)\end{array}$ \\
\hline $\begin{array}{l}\text { No. of new opioid } \\
\text { prescriptions }\end{array}$ & 67,717 & 99,540 & 118,424 & 89,136 \\
\hline $\begin{array}{l}\text { Eligible } \\
\text { beneficiaries with } \\
\text { new long-term } \\
\text { opioid episode } \ddagger\end{array}$ & 6,738 & 10,121 & 8,829 & $\begin{array}{c}7,639 \\
(12.40 \%)\end{array}$ \\
$\begin{array}{l}(12.80 \%) \\
(9.65 \%)\end{array}$ \\
$\begin{array}{l}\text { No. of new } \\
\text { long-term opioid } \\
\text { episodes }\end{array}$ & 6,837 & 10,320 & 8,970 & 7,727 \\
\hline
\end{tabular}

${ }^{*}$ Refers to all beneficiaries with at least 10 months eligibility. $\dagger$ Refers to all eligible beneficiaries who have at least one opioid Rx. The percentage of eligible beneficiaries with at least one opioid $\mathrm{Rx}$ is obtained using the number of beneficiaries with at least 10 months eligibility as the denominator.

$\$$ Refers to patients who were new long-term opioid users. The percentage of new long-term opioid users is obtained using the number of eligible beneficiaries with at least one opioid $\mathrm{Rx}$ as the denominator. §Estimates for the year 2016 were calculated using 5\% National Medicare data from January 1 through September 30, 2016. in 2016. Further analyses at the event level show that of the 67,717 new opioid prescriptions dispensed to eligible Medicare beneficiaries in $2013,10.10 \%(6,837)$ resulted in long-term episodes. By 2016, this number decreased to $8.67 \%$ of the 89,136 new opioid prescriptions during the first 9 months in that year.

\section{Characteristics of Beneficiaries with New Opioid Use}

The characteristics of Medicare beneficiaries who had at least one new opioid prescription during each study year is shown in Table 3. From 2013 to 2016, between 54,335 to 91,531 elderly Medicare beneficiaries received at least one new opioid prescription each year. Most of the beneficiaries were women $(61.76 \%-$ $67.40 \%$ ), over $90 \%$ of them were white, with a mean age of approximately 76 years old. Overall, among eligible beneficiaries with at least one new opioid prescription, approximately $17 \%$ had cancer and approximately $9 \%$ had both cancer and CNCP for each year in the study period. The proportion of individuals with CNCP among eligible beneficiaries with at least one new opioid prescription decreased from $25.63 \%$ in 2013 to $20.74 \%$ in 2016 . When analyses were conducted at the event level, on average, each individual accounted for between $1.25(67,717$ new opioid prescriptions among 54,335 unique beneficiaries) and 1.19 (89,316 new prescriptions among 74,881 unique beneficiaries) new opioid prescriptions during the study year, in 2013 and 2016, respectively. The characteristics of all new opioid prescriptions at the event level are provided in Table 4.

\section{Beneficiaries with New Long-Term Opioid Use Episodes}

Table 5 presents the demographic and clinical characteristics of eligible Medicare beneficiaries with new long-term opioid use episodes for each calendar year from 2013 to 2016. Across all the study years, a majority of the long-term opioid users were women $(\sim 65 \%-69 \%)$, white $(\sim 92 \%)$, and had a mean age of approximately 76 years. In 2013, $13.30 \%$ of long-term opioid users were identified as having cancer, and this number increased to $15.67 \%$ in 2016 . In contrast, the percentage of long-term opioid users with CNCP decreased from $30.25 \%$ in 2013 to $27.36 \%$ in 2016 . Similarly, a decrease in the percentage of long-term opioid users with both cancer and CNCP was seen over the study period (10.76\% in 2013 to $9.75 \%$ in 2016). Characteristics of all the long-term episodes at the event level are provided in Table 6. 
Long-Term Opioid Use Among Older Adults

Table 3. Characteristics of eligible Medicare beneficiaries with new opioid use by underlying conditions, 2013 to 2016.

\begin{tabular}{|c|c|c|c|c|}
\hline Characteristics & $2013(\mathrm{n}=54,355)$ & $2014(n=79,045)$ & $2015(n=91,531)$ & $2016 *(\mathrm{n}=74,881)$ \\
\hline Age mean (SD) & $76.18(7.63)$ & $75.89(7.52)$ & $75.66(7.40)$ & $75.68(7.63)$ \\
\hline \multicolumn{5}{|l|}{ Gender } \\
\hline Female & $36,090(66.40 \%)$ & $50,417(63.78 \%)$ & $56,957(62.23 \%)$ & $46,264(61.78 \%)$ \\
\hline \multicolumn{5}{|l|}{ Race } \\
\hline White & $49,985(91.96 \%)$ & $72,303(91.47 \%)$ & $83,535(91.26 \%)$ & $68,227(91.11 \%)$ \\
\hline African American & $3,192(5.87 \%)$ & $4,776(6.04 \%)$ & $5,476(5.98 \%)$ & $4,477(5.98 \%)$ \\
\hline Other & $1,178(2.17 \%)$ & $1,966(2.49 \%)$ & $2,520(2.75 \%)$ & $2,177(2.91 \%)$ \\
\hline \multicolumn{5}{|l|}{ Region } \\
\hline South & $22,260(40.95 \%)$ & $33,376(42.22 \%)$ & $40,120(43.83 \%)$ & $33,283(44.45 \%)$ \\
\hline Midwest & $15,079(27.74 \%)$ & $20,895(26.43 \%)$ & $22,624(24.72 \%)$ & $18,201(24.31 \%)$ \\
\hline West & $8,000(14.72 \%)$ & $12,716(16.09 \%)$ & $15,233(16.64 \%)$ & $12,715(16.98 \%)$ \\
\hline Northeast & $9,016(16.59 \%)$ & $12,058(15.25 \%)$ & $13,554(14.81 \%)$ & $10,682(14.27 \%)$ \\
\hline \multicolumn{5}{|l|}{ LIS enrollment } \\
\hline Yes & $5,260(9.68 \%)$ & $6,254(7.91 \%)$ & $6,252(6.83 \%)$ & $4,851(6.48 \%)$ \\
\hline Cancer & $9,232(17.0 \%)$ & $14,123(17.87 \%)$ & $17,007(18.58 \%)$ & $14,101(18.83 \%)$ \\
\hline $\mathrm{CNCP}$ & $13,932(25.63 \%)$ & $19,049(24.10 \%)$ & $21,626(23.63 \%)$ & $15,528(20.74 \%)$ \\
\hline Cancer and CNCP & $5,198(9.56 \%)$ & $7,302(9.24 \%)$ & $8,611(9.41 \%)$ & $5,947(7.94 \%)$ \\
\hline $\begin{array}{l}\text { No Cancer/CNCP/Cancer } \\
\& \text { CNCP }\end{array}$ & $25,993(47.82 \%)$ & $38,571(48.80 \%)$ & $44,287(48.38 \%)$ & $39,305(52.49 \%)$ \\
\hline
\end{tabular}

Abbreviations: CNCP, chronic non-cancer pain; LIS, low income status; SD, standard deviation.

${ }^{\star}$ Estimates for the year 2016 were calculated using 5\% National Medicare data from January 1 through September 30, 2016.

Table 4. Baseline characteristics of eligible Medicare beneficiaries with new opioid use event by year, 2013 to 2016.

\begin{tabular}{|c|c|c|c|c|}
\hline Characteristics & $2013(n=67,717)$ & $2014(n=99,540)$ & $2015(n=118,424)$ & $2016 *(n=89,136)$ \\
\hline Age mean (SD) & $76.22(7.61)$ & $75.95(7.50 \%)$ & $75.72(7.37)$ & $75.74(7.32)$ \\
\hline \multicolumn{5}{|l|}{ Gender } \\
\hline Female & $45,295(66.89 \%)$ & $64,181(64.48 \%)$ & $74,358(62.79 \%)$ & $53,339(62.08 \%)$ \\
\hline \multicolumn{5}{|l|}{ Race } \\
\hline White & $62,322(92.03 \%)$ & 91,124 (91.55\%) & 108,115 (91.29\%) & $81,189(91.08 \%)$ \\
\hline African American & $3,935(5.81 \%)$ & $6,030(6.06 \%)$ & 7,161 (6.05\%) & $5,372(6.03 \%)$ \\
\hline Other & $1,460(2.16 \%)$ & $2,386(2.40 \%)$ & $3,148(2.66 \%)$ & $2,575(2.89 \%)$ \\
\hline \multicolumn{5}{|l|}{ Region } \\
\hline South & $27,860(41.14 \%)$ & $41,965(42.16 \%)$ & $51,915(43.84 \%)$ & $39,659(44.49 \%)$ \\
\hline Midwest & $18,744(27.68 \%)$ & $26,602(26.72 \%)$ & $29,415(24.84 \%)$ & $21,725(24.37 \%)$ \\
\hline West & $9,921(14.65 \%)$ & $15,901(15.97 \%)$ & $19,716(16.65 \%)$ & $15,174(17.02 \%)$ \\
\hline Northeast & $11,192(16.53 \%)$ & $15,072(15.14 \%)$ & $17,378(14.67 \%)$ & $12,578(14.11 \%)$ \\
\hline \multicolumn{5}{|l|}{ LIS enrollment } \\
\hline Yes & $6,447(9.52 \%)$ & $7,650(7.69 \%)$ & $7,938(6.70 \%)$ & $5,752(6.45 \%)$ \\
\hline Cancer & $11,397(16.83 \%)$ & $17,530(17.61 \%)$ & $21,603(18.24 \%)$ & $16,614(18.64 \%)$ \\
\hline $\mathrm{CNCP}$ & $15,741(23.25 \%)$ & $21,761(21.86 \%)$ & $25,049(21.15 \%)$ & $16,799(18.85 \%)$ \\
\hline Cancer and $\mathrm{CNCP}$ & $5,506(8.13 \%)$ & 7,781 (7.82\%) & $9,193(7.76 \%)$ & 6,161 (6.91\%) \\
\hline $\begin{array}{l}\text { No Cancer/CNCP/Cancer } \\
\& \mathrm{CNCP}\end{array}$ & $35,073(51.79 \%)$ & $52,468(52.71 \%)$ & $62,579(52.84 \%)$ & $49,562(55.60 \%)$ \\
\hline
\end{tabular}

Abbreviations: CNCP, chronic non-cancer pain; LIS, low income status; SD, standard deviation.

${ }^{\star}$ Estimates for the year 2016 were calculated using 5\% National Medicare data from January 1 through September 30, 2016. 
Pain Physician: January/February 2021 24:31-40

Table 5. Characteristics of Medicare beneficiaries with new long-term opioid episodes by year, 2013 to 2016.

\begin{tabular}{|c|c|c|c|c|}
\hline Characteristics & $2013(n=6,738)$ & $2014(n=10,121)$ & $2015(n=8,829)$ & $2016 *(n=7,639)$ \\
\hline Age mean (SD) & $76.67(8.02)$ & $76.22(7.77)$ & $76.31(7.84)$ & $76.36(7.84)$ \\
\hline \multicolumn{5}{|l|}{ Gender } \\
\hline Female & $4,661(69.17 \%)$ & $6,801(67.20 \%)$ & $5,898(66.80 \%)$ & $4,990(65.32 \%)$ \\
\hline \multicolumn{5}{|l|}{ Race } \\
\hline White & $6,256(92.85 \%)$ & $9,345(92.33 \%)$ & $8,089(91.62 \%)$ & $6,980(91.37 \%)$ \\
\hline African American & $347(5.15 \%)$ & $569(5.62 \%)$ & $530(6.00 \%)$ & $465(6.09 \%)$ \\
\hline Other & $135(2.00 \%)$ & $207(2.05 \%)$ & $210(2.38 \%)$ & $194(2.54 \%)$ \\
\hline \multicolumn{5}{|l|}{ Region } \\
\hline South & $2,804(41.61 \%)$ & $4,419(43.66 \%)$ & $3,895(44.12 \%)$ & $3,434(44.95 \%)$ \\
\hline Midwest & $1,864(27.66 \%)$ & $2,720(26.87 \%)$ & $2,284(25.87 \%)$ & $1,951(25.54 \%)$ \\
\hline West & $1,039(15.42 \%)$ & $1,610(15.91 \%)$ & $1,368(15.49 \%)$ & $1,227(16.06 \%)$ \\
\hline Northeast & $1,031(15.30 \%)$ & $1,372(13.56 \%)$ & $1,282(14.52 \%)$ & $1,027(13.44 \%)$ \\
\hline \multicolumn{5}{|l|}{ LIS enrollment } \\
\hline Yes & $996(14.78 \%)$ & $1,273(12.58 \%)$ & $1,006(11.39 \%)$ & $816(10.68 \%)$ \\
\hline Cancer & $896(13.30 \%)$ & $1,434(14.17 \%)$ & $1,380(15.63 \%)$ & $1,197(15.67 \%)$ \\
\hline $\mathrm{CNCP}$ & $2,038(30.25 \%)$ & $2,909(28.74 \%)$ & $2,622(29.70 \%)$ & $2,090(27.36 \%)$ \\
\hline Cancer and $\mathrm{CNCP}$ & $725(10.76 \%)$ & $996(9.84 \%)$ & $954(10.81 \%)$ & $745(9.75 \%)$ \\
\hline $\begin{array}{l}\text { No Cancer/CNCP/Cancer } \\
\& \text { CNCP }\end{array}$ & $3,079(45.70 \%)$ & $4,782(47.25 \%)$ & $3,873(43.87 \%)$ & 3,607 (47.22\%) \\
\hline
\end{tabular}

Abbreviations: CNCP, chronic non-cancer pain; LIS, low income status; SD, standard deviation.

${ }^{\star}$ Estimates for the year 2016 were calculated using 5\% National Medicare data from January 1 through September 30, 2016.

Table 6. Baseline characteristics of new long-term opioid events among Medicare beneficiaries by year, 2013 to 2016.

\begin{tabular}{|c|c|c|c|c|}
\hline Characteristics & $2013(n=6,837)$ & $2014(\mathrm{n}=10,320)$ & $2015(\mathrm{n}=8,970)$ & $2016 *(n=7,727)$ \\
\hline Age mean (SD) & $76.67(8.02)$ & $76.22(7.78)$ & $76.28(7.83)$ & $76.37(7.84)$ \\
\hline \multicolumn{5}{|l|}{ Gender } \\
\hline Female & $4,734(69.24 \%)$ & 6,932 (67.17) & $5,988(66.76 \%)$ & $5,050(65.36 \%)$ \\
\hline \multicolumn{5}{|l|}{ Race } \\
\hline White & 6,352 (92.91\%) & 9,533 (92.37\%) & $8,222(91.66 \%)$ & $7,064(91.42 \%)$ \\
\hline African American & $348(5.09 \%)$ & $576(5.58 \%)$ & $534(5.95 \%)$ & $468(6.06 \%)$ \\
\hline Other & $137(2.00 \%)$ & $211(2.04 \%)$ & $214(2.39 \%)$ & $195(2.52 \%)$ \\
\hline \multicolumn{5}{|l|}{ Region } \\
\hline South & 2,852 (41.71\%) & $4,513(43.73 \%)$ & 3,959 (44.14\%) & $3,481(45.05 \%)$ \\
\hline Midwest & $1,890(27.64 \%)$ & $2,765(26.79 \%)$ & 2,319 (25.85\%) & $1,966(25.44 \%)$ \\
\hline West & $1,049(15.34 \%)$ & $1,648(15.97 \%)$ & $1,389(15.48 \%)$ & $1,242(16.07 \%)$ \\
\hline Northeast & $1,046(15.30 \%)$ & $1,394(13.51 \%)$ & $1,303(14.53 \%)$ & $1,038(13.43 \%)$ \\
\hline \multicolumn{5}{|l|}{ LIS enrollment } \\
\hline Yes & $1,011(14.79 \%)$ & $1,290(12.50 \%)$ & $1,021(11.38 \%)$ & $823(10.65 \%)$ \\
\hline Cancer & $910(13.31 \%)$ & $1,508(14.61 \%)$ & $1,429(15.93 \%)$ & $1,225(15.85 \%)$ \\
\hline $\mathrm{CNCP}$ & $1,922(28.11 \%)$ & $2,704(26.20 \%)$ & 2,398 (26.73\%) & $1,993(25.79 \%)$ \\
\hline Cancer and CNCP & $671(9.81 \%)$ & $865(8.38 \%)$ & $847(9.44 \%)$ & $701(9.07 \%)$ \\
\hline $\begin{array}{l}\text { No Cancer/CNCP/Cancer } \\
\& \text { CNCP }\end{array}$ & $3,334(48.76 \%)$ & $5,243(50.80 \%)$ & 4,296 (47.86\%) & $3,808(49.28 \%)$ \\
\hline
\end{tabular}

Abbreviations: CNCP, chronic non-cancer pain; LIS, low income status; SD, standard deviation.

${ }^{\star}$ Estimates for the year 2016 were calculated using 5\% National Medicare data from January 1 through September 30, 2016. 


\section{Geographic Variation in Long-Term Opioid Use Episodes}

Figures 2A, 2B, and 3 show the state-level maps for long-term opioid utilization among older adults enrolled in Medicare in the United States in 2013, 2016, and the trend across the study years, respectively. Data shown in the maps represent the proportion of Medicare beneficiaries with new long-term opioid episodes each year, broken down by quartiles in Figs. 2A and 2B, and by the median in Fig. 3. From 2013 to 2016, a consistently high rate of utilization of long-term opioids is seen in the Southern states followed by the Midwest region. However, the use of long-term opioids in the Midwest region shows a decline.

\section{Discussion}

This study estimates the patterns of long-term prescription opioid use among older adults on Medicare and helps fill a critical gap in the literature. The individuals examined in this study were from a randomly drawn sample of at least 2.3 million Medicare enrollees for each study year and provides estimates that are generalizable to the Medicare fee-for-service population. The patterns of utilization seen in this study are consistent with the known trends of the opioid epidemic in the Unites States (24). The Centers for Disease Control and Prevention (CDC) reports that the overall rate of opioid prescriptions in the Unites States peaked in 2012 and has been decreasing since then (25). Our findings show that new prescription opioid use among older adults continued to increase after 2012 and peaked in 2015; this time lag suggests a slower response to the opioid crisis in the elderly population. The geographic patterns in opioid use found in this study align with the CDC US prescribing rate maps that shows that the Southern region has higher prescribing rates than the rest of the country (26). Clinicians practicing in this region need to be more vigilant about their procedures behaviors to help contain the national opioid epidemic while providing adequate pain management for their patients. The unique strength of this study is that it provides annual trends from recent data from a nationally representative sample of older adults. It also provides a more complete picture by capturing both any opioid use and long-term opioid use patterns and characterizing these populations in terms of cancer and CNCP.

The current study found that the proportion of eligible Medicare beneficiaries with a new opioid prescription was $6.64 \%$ in 2013 and $8.14 \%$ in 2016 . A study by Landsman-Blumberg et al (27) examined opioid utilization patterns between 2006 and 2012 in a population of Medicare Advantage and Medigap enrollees. They found that $6.2 \%$ of individuals engaged in any opioid use, which is closely aligned with the range reported in the current study (27). The proportion of all eligible individuals with long-term use ranged between $0.82 \%$ and $0.83 \%$ in the current study, whereas the LandsmanBlumberg et al (27) study found that $0.27 \%$ of individuals engaged in long-term opioid use. The proportions in our study were relatively higher as we examined a

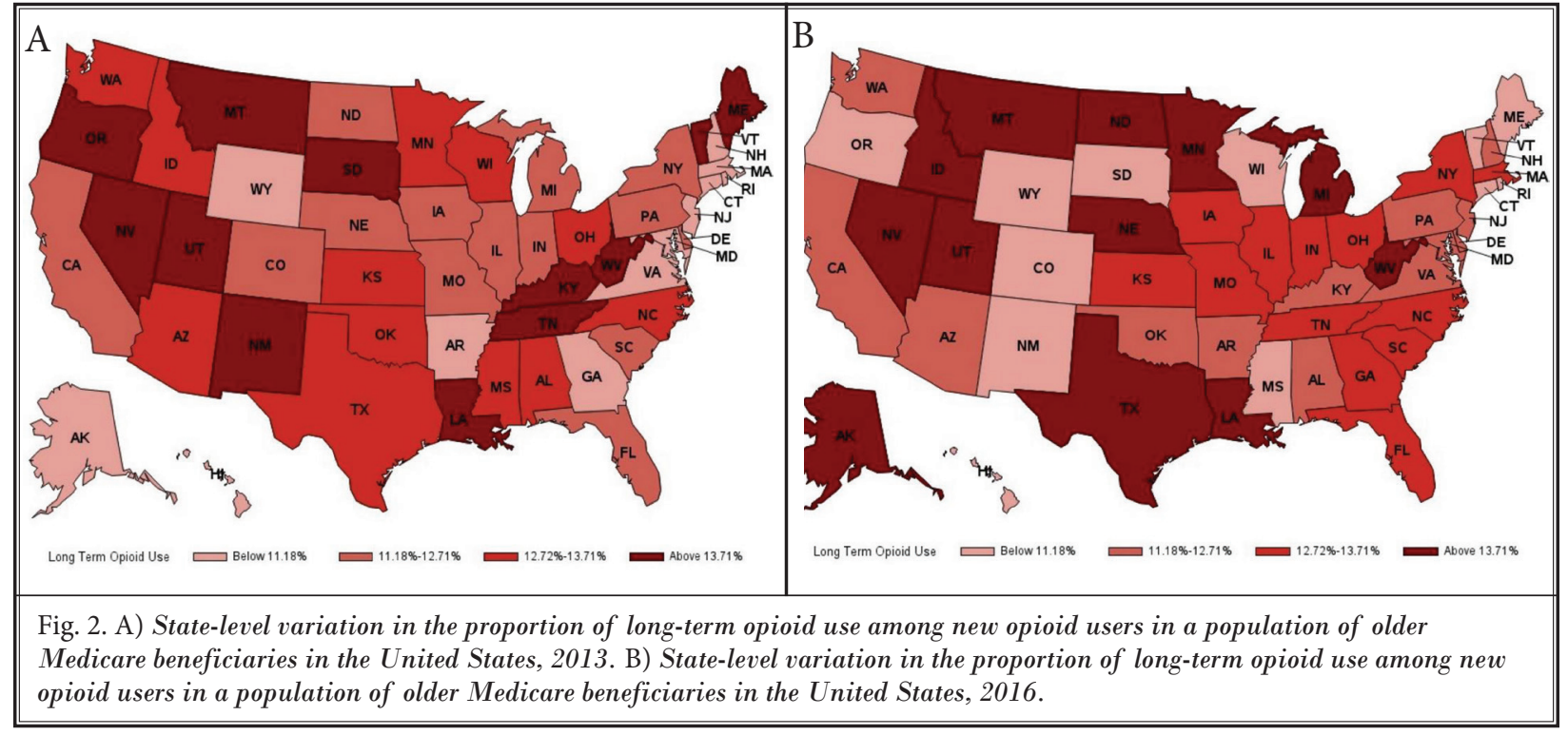




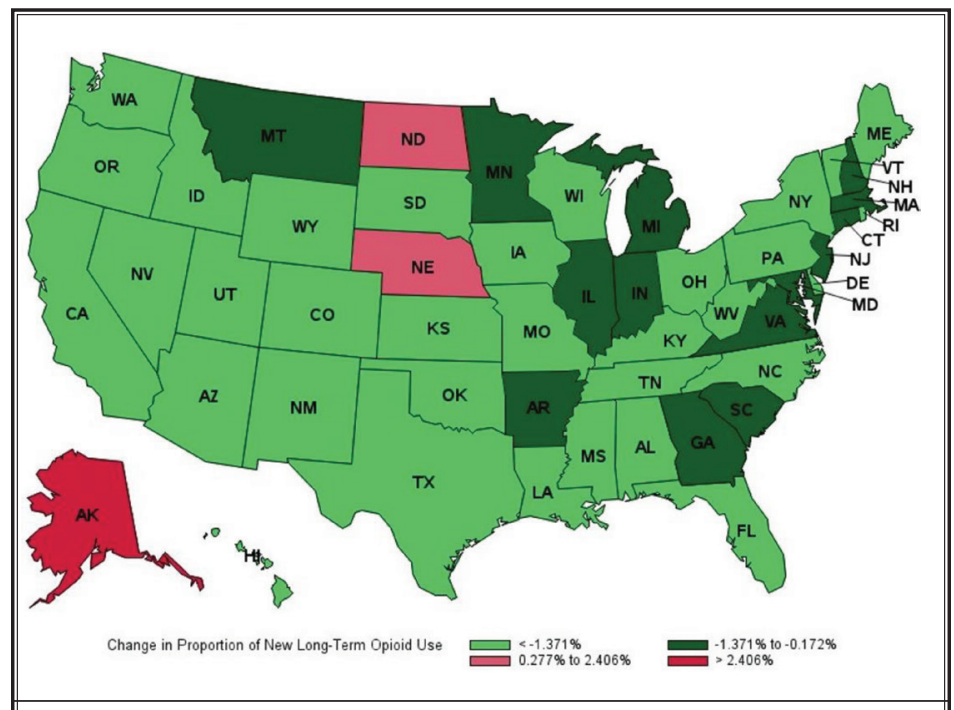

Fig. 3. State-level variation in change in proportion of long-term opioid use among new opioid users in older Medicare beneficiaries in the United States between 2013 and 2016.

Year-over-year changes in opioid use show interesting patterns in this study. The proportion of older adults with a new opioid prescription increased from 2013 to 2015 and decreased in 2016, whereas the proportion of older adults with long-term opioid use increased from 2013 to 2014, and then decreased in 2016. This decreasing trend in 2016 has the potential to be promising given that opioids were widely known to be overprescribed. National prescription audit data from IQVIA reports that the opioid new therapy starts decreased consistently from the last quarter of 2015 through 2017 (32). The decrease of prescriptions in 2016 may also be explained by tightening regulations around the prescription of opioids by managed care organizations, physician groups, government agencies, and state legislatures (22,28,33-37). In early 2016, the CDC released guidelines to primary care physicians to urge caution and

population consisting of exclusively older adults as opposed to all adults reported in the Landsman-Blumberg et al (27) study. The current study also found that the proportion of new opioid users that transitioned to having at least one long-term event in the year was $12.4 \%$ in 2013 and $10.2 \%$ in 2016 . This proportion increased from 2013 to 2014, but by 2016, it had decreased. This may be attributable to the CDC guideline for prescribing opioids for chronic pain released in late 2015 to reduce the risk of long-term opioid use (28). Musich et al (29) found the proportion of individuals who progressed to long-term use to be lower, $6.49 \%$, among enrollees of a large Medicare Supplement plan provided by a single insurer in 2016. Examining opioid use among individuals enrolled in Medicare Supplemental insurance can be valuable as a complement to the current study, but may not be generalizable to a national sample.

Previous findings have reported that the prevalence of long-term opioid use among older adults with CNCP varied anywhere from $1.8 \%$ to $18.9 \%(11,30,31)$. This wide variation in reported rates is probably attributed to the variation in the period, geographic location, and the health care coverage of the populations examined. Although the findings of the current study still lie within this reported range, in the current study long-term opioid use was examined among all eligible individuals and not just those with CNCP conditions, so the rates may not be directly comparable. care in prescribing opioids for chronic pain (5). In addition, several states implemented laws restricting the dosage or duration of supply of new opioid prescriptions, mandating prescription drug monitoring program checks, increasing provider education, access to medication-assisted treatment options, and operation of pain clinics (32).

Other interesting findings from this study are related to the trends in the presence of cancer and CNCP diagnoses in the populations of interest. Over the duration of the study period, the prevalence of cancer diagnosis among patients with a new opioid prescription increased consistently from $17.0 \%$ in 2013 to $18.8 \%$ in 2016, whereas the prevalence of any CNCP diagnoses in the same population decreased consistently from $25.6 \%$ in 2013 to $20.7 \%$ in 2016 . Among patients with a new long-term opioid use event, the prevalence of cancer diagnoses increased from $13.3 \%$ in 2013 to $15.7 \%$ in 2016, and the prevalence of CNCP diagnoses decreased from $30.2 \%$ in 2013 to $27.4 \%$ in 2016 . The characteristics of the opioid use population show a steady shift of opioid use over time from CNCP diagnoses to cancer. This shift may be related to increasing scrutiny of excessive opioid use among non-cancer patients and the relative lack of literature studying overprescribing of opioids among cancer patients. Interestingly, this study also examined opioid use among patients for whom neither CNCP nor cancer diagnosis codes could be identified in this data. This group of patients with 
no identifiable cause in the database for opioid use still comprised a large portion of the population: $47.8 \%$ to $52.5 \%$ of any new opioid use and $43.9 \%$ to $47.3 \%$ of long-term opioid use. These patterns demonstrate the need to study opioid use specifically among those with cancer and in the general population who may not have identifiable diagnoses in claims data. These patterns demonstrate the disadvantages of using administrative claims data for research and the need for recording detailed information in claims forms to facilitate accurate capture of health care quality and utilization trends. The geographic patterns in long-term opioid use from this study are also consistent with previous studies that show a higher burden from the opioid epidemic in the Southern and Midwestern regions of the United States (38). Finally, this study does not draw any insights as to the appropriateness or the benefit-risk assessment involved in every opioid prescription. Pain management in older adults is a challenging therapeutic area that carries risks of undertreatment or overmedication, and many available therapeutic choices, including opioids, have risks of adverse reactions and contraindications.

The findings of this study have to be evaluated in light of a few critical limitations. First, this study used Medicare fee-for-service administrative claims data to capture prescription fill patterns. However, these data are often limited. They do not allow for the capture of prescriptions paid for with cash or for the inclusion of beneficiaries enrolled in Medicare Advantage plans. The claims data may also be incomplete because it only captures those diagnoses and prescriptions that were recorded on claim forms. These data also include the location of the beneficiary's residence, the accuracy of which depends on the quality of the reporting. Second, this study did not evaluate the appropriateness of pre- scriptions under study. It is not possible to evaluate the quality of prescribing trends reported in this study from administrative claims data. Third, this study only examined long-term use episodes among patients who were defined as opioid-naive. However, it was not possible to assess if patients had unused opioid medications leftover from previous prescriptions or if they were borrowing or sharing their medications. Fourth, estimates captured for 2016 could only utilize data from 9 months of the year to capture 90-day long-term-use episodes. Therefore opioid use from 2016 may not be fully captured. Finally, this study captures prescription fill patterns, but it was not possible to assess the frequency of actual medication use.

\section{Conclusions}

This study helps to estimate nationally generalizable trends of opioid use patterns among older adults and characterizes the population filling opioid prescriptions. Further research is needed to evaluate the continued trends after 2016 and the outcomes of patients with long-term opioid use.

\section{Acknowledgments}

Author contributions: YY, JB, and MS participated in the design of the study. MS and SR conducted the programming and data analyses. All authors participated in the interpretation of results. SR, YY, and MS prepared the first draft of the manuscript, and all authors provided comments and edits and approved the final version of the manuscript. YY, JB, SR, and IE obtained funding for this study. SR, MS, JB, and $Y Y$ had full access to all the data in the study and take responsibility for the integrity of the data and the accuracy of the data analyses.

Appendix table available at painphysicianjournal.com

\section{References}

1. Kennedy J, Roll JM, Schraudner T, Murphy S, McPherson S. Prevalence of persistent pain in the U.S. adult population: New data from the 2010 National Health Interview Survey. J Pain 2014; 15:979-984.

2. Patel KV, Guralnik JM, Dansie EJ, Turk DC. Prevalence and impact of pain among older adults in the United States: Findings from the 2011 National Health and Aging Trends Study. Pain 2013; 154:2649-2657.
3. Reid MC, Eccleston C, Pillemer K. Management of chronic pain in older adults. BMJ 2015; 350:h532.

4. American Geriatrics Society Panel on the Pharmacological Management of Persistent Pain in Older Persons. Pharmacological management of persistent pain in older persons. Pain Med 2009; 10:1062-1083.

5. Centers For Disease Control And Prevention Public Health Service U S Department Of Health And Human
Services. Guideline for prescribing opioids for chronic pain. J Pain Palliat Care Pharmacother 2016; 30:138-140.

6. Zedler B, Xie L, Wang L, et al. Risk factors for serious prescription opioidrelated toxicity or overdose among Veterans Health Administration patients. Pain Med 2014; 15:1911-1929.

7. Boudreau D, Von Korff $M$, Rutter $\mathrm{CM}$, et al. Trends in long-term opioid therapy for chronic non-cancer pain. Pharmacoepidemiol Drug Saf 2009; 
18:1166-1175.

8. Gloth FM. Pharmacological management of persistent pain in older persons: Focus on opioids and nonopioids. J Pain 2011; 12(3 Suppl 1):S14-S2O.

9. Barkin RL, Beckerman M, Blum SL, Clark FM, Koh E-K, Wu DS. Should nonsteroidal anti-inflammatory drugs (NSAIDs) be prescribed to the older adult? Drugs Aging 2010; 27:775-789.

10. Centers for Disease Control and Prevention. America's Drug Overdose Epidemic: Data to Action. Centers for Disease Control and Prevention. Published December 16, 2020. Available at: https://www.cdc.gov/ injury/features/prescription-drugoverdose/index.html. Accessed December 17, 2020.

11. Campbell $\mathrm{Cl}$, Weisner C, LeResche $L$, et al. Age and gender trends in long-term opioid analgesic use for noncancer pain. Am J Public Health 2010; 100:2541-2547.

12. Steinman MA, Komaiko KDR, Fung $K Z$, Ritchie CS. Use of opioids and other analgesics by older adults in the United States, 1999-2010. Pain Med 2015; 16:319-327.

13. Centers for Medicare \& Medicaid Services. 2016 Medicare enrollment section. Available at: www.cms.gov/ Research-Statistics-Data-and-Systems/ Statistics-Trends-and-Reports/ CMSProgramStatistics/2016/2016_ Enrollment. Accessed April 9, 2020.

14. Centers for Medicare \& Medicaid Services. Opioid oral morphine milligram equivalent (MME) conversion factors. Available at: www.cms. gov/Medicare/Prescription-DrugCoverage/PrescriptionDrugCovContra/ Downloads/Opioid-Morphine-EQConversion-Factors-Aug-2017.pdf. Accessed June 10, 2020.

15. Dunn KM, Saunders KW, Rutter CM, et al. Opioid prescriptions for chronic pain and overdose: A cohort study. Ann Intern Med 2010; 152:85-92.

16. Argoff CE, Silvershein DI. A comparison of long- and short-acting opioids for the treatment of chronic noncancer pain: Tailoring therapy to meet patient needs. Mayo Clin Proc 2009; 84:602-612.

17. Arai T, Kashimoto $\mathrm{Y}$, Ukyo Y, Tominaga Y, Imanaka K. Two placebo-controlled, randomized withdrawal studies to evaluate the fentanyl 1 day patch in opioid-naïve patients with chronic pain. Curr Med Res Opin 2015; 31:2207-2218.

18. Reid MC, Bennett DA, Chen WG, et al. Improving the pharmacologic management of pain in older adults: Identifying the research gaps and methods to address them. Pain Med 2011; 12:1336-1357.

19. Sullivan MD, Edlund MJ, Fan M-Y, Devries A, Brennan Braden J, Martin $B C$. Trends in use of opioids for noncancer pain conditions 2000-2005 in commercial and Medicaid insurance plans: The TROUP study. Pain 2008; 138:440-449.

20. Busse JW, Wang L, Kamaleldin M, et al. Opioids for chronic noncancer pain: A systematic review and meta-analysis. JAMA 2018; 320:2448-2460.

21. Niknejad B, Bolier R, Henderson CR, et al. Association between psychological interventions and chronic pain outcomes in older adults: A systematic review and meta-analysis. JAMA Intern Med 2018; 178:830-839.

22. Chou R, Fanciullo G), Fine PG, et al. Clinical guidelines for the use of chronic opioid therapy in chronic noncancer pain.J Pain 2009; 10:113-130.

23. Mayo Clinic Proceedings. A comparison of long- and short-acting opioids for the treatment of chronic noncancer pain: Tailoring therapy to meet patient needs. Published July 21, 2019. Available at: www.mayoclinicproceedings.org/ article/Soo25-6196(11)60749-o/fulltext. Accessed July 21, 2019.

24. Centers for Disease Control and Prevention. Understanding the epidemic. Published July 24, 2019. Available at: www.cdc.gov/drugoverdose/epidemic/ index.html. Accessed December 3, 2019.

25. Centers for Disease Control and Prevention. Prescribing practices. Published August 20, 2019. Available at: www.cdc.gov/drugoverdose/data/ prescribing/prescribing-practices. html. Accessed February 3, 2020.

26. Centers for Disease Control and Prevention. U.S. opioid prescribing rate maps. Published August 12, 2019. Available at: www.cdc.gov/ drugoverdose/maps/rxrate-maps. html. Accessed February 3, 2020.

27. Landsman-Blumberg PB, Katz N, Gajria K, et al. Health care resource use and cost differences by opioid therapy type among chronic noncancer pain patients. J Pain Res 2017; 10:1713-1722.

28. Dowell D, Haegerich TM, Chou R.
CDC guideline for prescribing opioids for chronic pain-United States, 2016. MMWR Recomm Rep 2016; 65(No. RR-1):1-49.

29. Musich S, Wang SS, Slindee L, Kraemer $S$, Yeh CS. Characteristics associated with transition from opioid initiation to chronic opioid use among opioidnaïve older adults. Geriatr Nurs 2019; 40:190-196.

30. Oh Gy, Abner EL, Fardo DW, Freeman PR, Moga DC. Patterns and predictors of chronic opioid use in older adults: A retrospective cohort study. PLoS One 2019; 14:e0210341.

31. Thielke SM, Simoni-Wastila L, Edlund $\mathrm{MJ}$, et al. Age and sex trends in longterm opioid use in two large American health systems between 2000 and 2005. Pain Med 2010; 11:248-256.

32. IQVIA. Medicine use and spending in the U.S. Published December 3, 2019. Available at: www.iqvia.com/insights/ the-iqvia-institute/reports/medicineuse-and-spending-in-the-us-reviewof-2017-outlook-to-2022. Accessed December 3, 2019.

33. Trescot AM, Helm S, Hansen $\mathrm{H}$, et al. Opioids in the management of chronic non-cancer pain: An update of American Society of the Interventional Pain Physicians' (ASIPP) Guidelines. Pain Physician 2008; 11 (2 Suppl):S5-S62.

34. McCarberg B. Responsible opioid prescribing: A physician's guide. Pain Med 2008; 9:759-760.

35. National Conference of State Legislatures. Prescribing policies: States confront opioid overdose epidemic. Published December 3, 2019. Available at: www.ncsl.org/research/ health/prescribing-policies-statesconfront-opioid-overdose-epidemic. aspx. Accessed December 3, 2019.

36. American Academy of Family Physicians. Chronic pain management and opioid misuse: $A$ public health concern (position paper). Available at: www.aafp.org/about/policies/all/painmanagement-opioid.html. Accessed February 3, 2020.

37. Munzing T. Physician guide to appropriate opioid prescribing for noncancer pain. Perm J 2017; 21:16-169.

38. Schieber LZ, Guy GP, Seth P, et al. Trends and patterns of geographic variation in opioid prescribing practices by state, United States, 20062017. JAMA Netw Open 2019; 2:e190665 
Appendix: Generic names and summary statistics of dosages (daily MME) of opioids identified in this study.

\begin{tabular}{|l|c|c|c|}
\hline Opioid Name & $\begin{array}{c}\text { Median } \\
\text { Daily MME }\end{array}$ & $\begin{array}{c}\text { MME 25th } \\
\text { Percentile }\end{array}$ & $\begin{array}{c}\text { MME 75th } \\
\text { Percentile }\end{array}$ \\
\hline Butorphanol & 13.46 & 11.67 & 25.00 \\
\hline Codeine & 18.41 & 13.50 & 28.13 \\
\hline Dihydrocodeine & 12.00 & 8.00 & 24.00 \\
\hline Fentanyl & 120.00 & 60.0 & 180.00 \\
\hline Hydrocodone & 30.00 & 20.00 & 40.00 \\
\hline Hydromorphone & 64.00 & 40.00 & 96.00 \\
\hline Levorphanol & 66.00 & 66.00 & 88.00 \\
\hline Meperidine & 25.00 & 15.00 & 39.47 \\
\hline Methadone & 120.00 & 60.00 & 180.00 \\
\hline Morphine & 60.00 & 40.00 & 120.00 \\
\hline Opium & 30.26 & 24.00 & 60.00 \\
\hline Oxycodone & 60.00 & 32.14 & 90.00 \\
\hline Oxymorphone & 120.00 & 60.00 & 180.00 \\
\hline Pentazocine & 74.00 & 55.50 & 111.00 \\
\hline Tapentadol & 90.00 & 60.00 & 150.00 \\
\hline Tramadol & 20.00 & 15.00 & 25.00 \\
\hline \hline
\end{tabular}

Abbreviations: MME, morphine milligram equivalents (as calculated according to reference 14). 